\title{
BMJ Open Prevalence and correlates of depression among black and Latino stroke survivors with uncontrolled hypertension: a cross-sectional study
}

\author{
Adebayo O Ogunlade, ${ }^{1}$ Stephen K Williams, ${ }^{1}$ Jennifer Joseph, ${ }^{1}$ \\ Deborah O Onakomaiya (D) , ${ }^{1}$ Joseph P Eimicke, ${ }^{2}$ Jeanne A Teresi, ${ }^{2,3}$ \\ Olajide Williams, ${ }^{4}$ Gbenga Ogedegbe, ${ }^{1}$ Tanya M Spruill ${ }^{1}$
}

To cite: Ogunlade $\mathrm{AO}$,

Williams SK, Joseph J, et al. Prevalence and correlates of depression among black and Latino stroke survivors with uncontrolled hypertension: a cross-sectional study. BMJ Open 2020;10:e040461. doi:10.1136/ bmjopen-2020-040461

- Prepublication history for this paper is available online. To view these files, please visit the journal online (http://dx.doi org/10.1136/bmjopen-2020040461).

Received 14 May 2020 Revised 06 October 2020 Accepted 06 November 2020

\section{Check for updates}

(c) Author(s) (or their employer(s)) 2020. Re-use permitted under CC BY-NC. No commercial re-use. See rights and permissions. Published by BMJ.

${ }^{1}$ Center for Healthful Behavior Change, Department of Population Health, New York University Grossman School of Medicine, New York, New York, USA

${ }^{2}$ Research Division, Hebrew Home at Riverdale, Bronx, New York, USA

${ }^{3}$ Columbia University Stroud Center, New York State

Psychiatric Institute, New York, New York, USA

${ }^{4}$ Columbia University Medical Center, New York, New York, USA

Correspondence to

Adebayo 0 Ogunlade;

adebayo.ogunlade@nyulangone. org

\section{ABSTRACT}

Objective To examine the prevalence and correlates of depression in a cohort of black and Hispanic stroke survivors with uncontrolled hypertension.

Setting Baseline survey data from 10 stroke centres across New York City.

Participants Black and Hispanic stroke survivors with uncontrolled hypertension $(n=450)$.

Outcome measures Depressive symptoms were assessed with the 8-item Patient Reported Outcomes Measurement Information System (PROMIS) measure. Depression was defined as a PROMIS score $\geq 55$. Other data collected included clinical factors, health-related quality of life (EuroQoL five dimensions (EQ-5D)), functional independence (Barthel Index, BI), stroke-related disability (Modified Rankin Score), physical function (PROMIS Physical Function) and executive functioning (Frontal Assessment Battery).

Results The mean age was $61.7 \pm 11.1$ years, $44 \%$ of participants were women and $51 \%$ were black. Poststroke depression was noted in $32 \%$ of the cohort. Examining bivariate relationships, patients with depression were observed to have poorer function and quality of life as evidenced by significantly lower PROMIS physical function scores ( $36.9 \pm 8.32$ vs $43.4 \pm 10.19, p<0.001)$; Bl scores (79.9 \pm 19.2 vs $88.1 \pm 15.1, p<0.001)$; EQ-5D scores $(0.66 \pm 0.24$ vs $0.83 \pm 0.17, p<0.001)$ and higher Rankin scores $(2.10 \pm 1.00$ vs $1.46 \pm 1.01, p<0.001)$ compared with those without depression. Multivariate (model adjusted) significant correlates of depression included lower self-reported quality of life $(\mathrm{OR}=0.02(\mathrm{Cl} 0.004$ to 0.12 ) being younger ( $\mathrm{OR}=0.94 ; 95 \% \mathrm{Cl} 0.91$ to 0.97$)$; not married ( $\mathrm{OR}=0.46$; $\mathrm{Cl} 0.24$ to 0.89$)$ ); and foreignborn $(0 \mathrm{R}=3.34,95 \% \mathrm{Cl} 1.4$ to 7.97$)$. There was a trend for higher comorbidity to be uniquely associated with depression ( $\geq 3$ comorbid conditions, OR=1.49, 95\% Cl 1.00 to 2.23 ).

Conclusions Poststroke depression is common among black and Hispanic stroke survivors with higher rates noted among foreign-born patients and those with high comorbidity. These findings highlight the importance of screening for depression in minority stroke survivors. Trial registration number http://www.clinicaltrials.gov. Unique identifier: NCT01070056.
Strengths and limitations of this study

- This is the first study to specifically examine poststroke depression among community-dwelling minority stroke survivors.

- The definition of depression was based on patient self-report using an interview administered validated screening tool, allowing the inclusion of undiagnosed depression.

Data were only assessed in select cohort that survived the stroke event and recovered sufficiently to be discharged to the community.

- Findings can only be generalised to black and Hispanic stroke survivors as it did not consist of other minority groups.

\section{INTRODUCTION}

Poststroke depression (PSD) affects approximately one-third of stroke survivors, either in the early or in the late stages after stroke. ${ }^{12}$ Depression among stroke survivors is associated with long-term physical disability, ${ }^{3}$ cognitive impairments ${ }^{4}$ and increased mortality risk. ${ }^{5}$ At the same time, PSD remains underdiagnosed, particularly in minority populations ${ }^{6}$ and little is known about correlates of PSD in community-dwelling minorities. Most studies that have evaluated PSD among minorities have either focused mainly on Hispanics or included very few $(<25 \%)$ black patients. ${ }^{37}$ Early identification of depression in this vulnerable cohort is essential to optimise poststroke recovery and decrease the high morbidity and mortality that is especially prevalent in minority populations post stroke. Our study addresses this critical knowledge gap by examining the prevalence and correlates of depression among communitydwelling black and Hispanic stroke survivors with uncontrolled hypertension. 
Table 1 Cohort characteristics

\begin{tabular}{|c|c|c|c|c|}
\hline Variables & Total $(n=445)$ & $\begin{array}{l}\text { Without depression } \\
(\mathrm{n}=301,67.6 \%)\end{array}$ & $\begin{array}{l}\text { With depression } \\
(n=144,32.4 \%)\end{array}$ & $P$ value \\
\hline \multicolumn{5}{|l|}{ Sociodemographics } \\
\hline Female, n, (\%) & $196(44.0)$ & $118(39.2)$ & $78(54.2)$ & 0.003 \\
\hline Race, n (\%) & & & & 0.169 \\
\hline Black, non-Hispanic & $228(51.2)$ & $161(53.5)$ & $67(46.5)$ & \\
\hline Married/domestic partnership, n (\%) & $187(42.1)$ & $137(45.7)$ & $50(34.7)$ & 0.174 \\
\hline Less than high school education, n (\%) & $208(49.3)$ & $136(47.7)$ & $72(52.6)$ & 0.458 \\
\hline Annual household income $<$ US $\$ 25000, \mathrm{n}(\%)$ & $233(72.6)$ & $149(68.3)$ & $84(81.6)$ & 0.011 \\
\hline Foreign born, n (\%) & $321(72.5)$ & 209 (69.9) & $112(77.8)$ & 0.078 \\
\hline Diastolic blood pressure, mean (SD) & $87.91(12.54)$ & $88.28(12.89)$ & $87.14(11.79)$ & 0.370 \\
\hline \multicolumn{4}{|l|}{ Charlson Comorbidity Index, n (\%) } & 0.014 \\
\hline 0 comorbid conditions & $88(19.8)$ & $66(22.0)$ & $22(15.3)$ & \\
\hline 1-2 comorbid conditions & $220(49.5)$ & $155(51.7)$ & $65(45.1)$ & \\
\hline$\geq 3$ comorbid conditions & $136(30.6)$ & $79(26.3)$ & 57 (39.6) & \\
\hline $\begin{array}{l}\text { EuroQoL (EQ-5D; higher score indicates best } \\
\text { health), mean (SD) }\end{array}$ & $0.77(0.21)$ & $0.83(0.17)$ & $0.66(0.24)$ & $<0.001$ \\
\hline $\begin{array}{l}\text { Barthel Index (higher score indicates greater } \\
\text { independence), mean (SD) }\end{array}$ & $85.43(16.96)$ & $88.06(15.14)$ & $79.93(19.15)$ & $<0.001$ \\
\hline $\begin{array}{l}\text { PROMIS Physical Function (higher score indicates } \\
\text { greater functional ability), mean (SD) }\end{array}$ & $41.30(10.09)$ & $43.42(10.19)$ & $36.89(8.32)$ & $<0.001$ \\
\hline
\end{tabular}

EQ-5D, EuroQoL five dimension; PROMIS, Patient Reported Outcomes Measurement Information System.

\section{METHODS}

Sample: for these analyses, we used baseline data from a clinical trial of hypertension control strategies among 450 blacks and Hispanics with recent stroke ( $\approx 7$ months after index stroke) recruited from 10 stroke centres in New York City; the study design is discussed in detail elsewhere. ${ }^{8}$ All participants provided informed consent before inclusion in the study.

Measures: participants were interviewed at baseline to assess depressive symptoms over the past 7 days using the 8-item Patient Reported Outcomes Measurement Information System (PROMIS) Depression Short Form. ${ }^{9}$ This measure has been found to perform well among ethnically diverse groups, evidencing little differential item functioning of high magnitude. ${ }^{10}$ Internal consistency and unidimensionality estimates for the continuous PROMIS Depression scale for the current sample were high (ordinal alpha=0.949; McDonald's Omega total $=0.949$; Explained Common Variance=84.199).
Depression was defined as a PROMIS score $\geq 55$, which indicates at least mild depression according to the American Psychiatric Association classification. ${ }^{11}$ Other data collected included sociodemographic factors, current smoking and alcohol use, Charlson Comorbidity Index, ${ }^{12}$ health-related quality of life (EuroQoL five dimensions (EQ-5D)), ${ }^{13}$ functional independence (Barthel Index), ${ }^{14}$ physical function (PROMIS Physical Function Short Form), ${ }^{15}$ stroke-related disability (Modified Rankin Score) ${ }^{16}$ and executive functioning (Frontal Assessment Battery). ${ }^{17}$

Statistical approach: variables were summarised as mean \pm SD for continuous variables and percentage for categorical variables. Bivariate analyses were conducted using student t-tests and $\chi^{2}$ tests for continuous and categorical variables, respectively. Multivariate logistic regression was performed to assess correlates of depression by adjusting for independent risk factors significantly associated with depression in addition to potential confounders 
Table 2 Cross-sectional predictors of depression among blacks and Hispanics stroke survivors with uncontrolled hypertension ${ }^{*} \dagger$

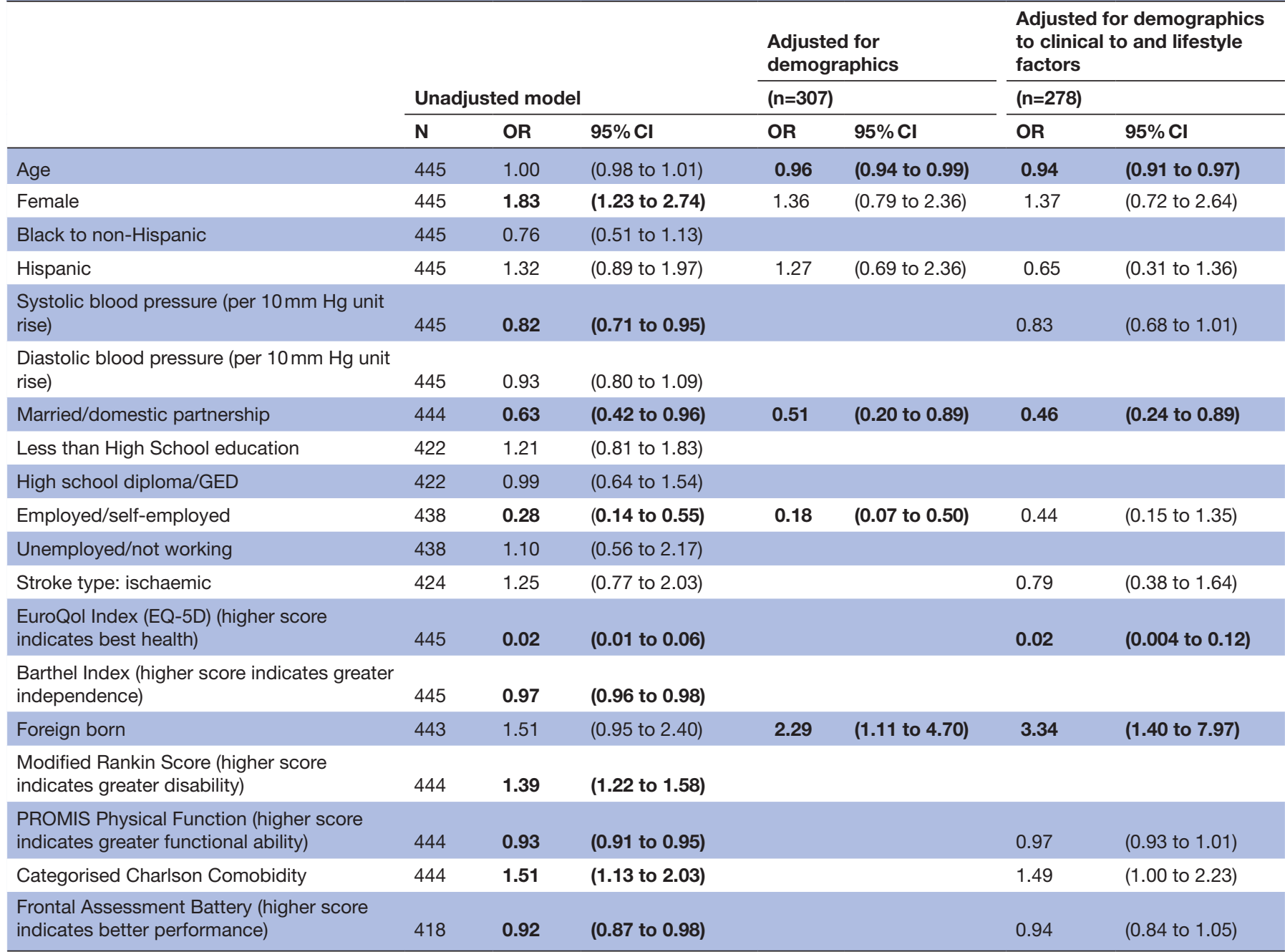

Significant relationships are in bold.

${ }^{*} \mathrm{OR}$ with $95 \% \mathrm{Cl}$ in predicting PSD.

†Variables not included in the adjusted models were removed because of collinearity.

GED, General Educational Development; HS, High School.

in bivariate analyses; variables not included in the adjusted models were removed because of collinearity.

The primary analyses were performed examining blood pressure (BP) using $10 \mathrm{~mm} \mathrm{Hg} \mathrm{units.} \mathrm{Logistic} \mathrm{regression}$ analyses were performed using generalised estimating equations assuming a binomial distribution with a logit link and robust estimates for variance. The motivation was to produce ORs as measures of association. These are appropriate summary statistics if they are not interpreted as relative risks. ${ }^{18}$

The assumption of linearity between the logit and the continuous predictor was examined using the BoxTidwell Test. ${ }^{19}$ This test was performed by obtaining the natural $\log$ of the continuous predictor and adding an interaction between the continuous predictor and its natural $\log$ variable to the logistic model. A significant interaction term is indicative of a violation of this assumption (non-linearity). The only predictor found to violate this assumption at the univariate level was the Modified Rankin Scale. This scale was previously removed from further analysis because of collinearity with other predictors. No violations were observed in the other two models.

Several sensitivity analyses were performed. The first was to treat depression as continuous and perform a linear regression predicting PROMIS Depression. Additionally, prevalence ratio statistics were estimated using several methods described in the text. Prevalence ratios were computed directly using three different methods as described by Barros and Hirakata ${ }^{20}$; and Coutinho et $a l^{21}$ The first method used was the log-binomial method (assumes a binomial distribution with a log link). The second method was interval censored survival analysis using a binomial distribution with a complementary loglog link (used in place of Cox proportional hazards). The third method was to use Poisson regression with a $\log$ 
Table 3 Sensitivity analysis using linear regression predicting continuous Patient Reported Outcomes Measurement Information System (PROMIS) depression $(n=278)$

\begin{tabular}{|c|c|c|c|c|c|c|c|}
\hline & \multicolumn{2}{|c|}{$\begin{array}{l}\text { Unstandardised } \\
\text { coefficients }\end{array}$} & \multirow{2}{*}{$\begin{array}{l}\text { Standardised } \\
\text { coefficients } \\
\text { Beta }\end{array}$} & \multirow[b]{2}{*}{$\mathbf{T}$} & \multirow[b]{2}{*}{$P$ value } & \multicolumn{2}{|l|}{$95.0 \% \mathrm{Cl}$ for $\mathrm{B}$} \\
\hline & B & SE & & & & Lower bound & Upper bound \\
\hline Age & -0.143 & 0.051 & -0.167 & -2.781 & 0.006 & -0.244 & -0.042 \\
\hline Female & 0.682 & 1.140 & 0.035 & 0.598 & 0.550 & -1.562 & 2.926 \\
\hline Married/domestic partnership & -1.051 & 1.124 & -0.054 & -0.934 & 0.351 & -3.264 & 1.163 \\
\hline Employed/self-employed & -1.802 & 1.397 & -0.077 & -1.290 & 0.198 & -4.553 & 0.948 \\
\hline Stroke type: ischaemic & 1.144 & 1.213 & 0.051 & 0.944 & 0.346 & -1.244 & 3.532 \\
\hline $\begin{array}{l}\text { EuroQoL Index (EQ-5D) (higher } \\
\text { score indicates best health) }\end{array}$ & -18.974 & 2.969 & -0.418 & -6.391 & $<0.001$ & -24.820 & -13.128 \\
\hline $\begin{array}{l}\text { Categorised Charlson } \\
\text { Comobidity }\end{array}$ & 0.522 & 0.763 & 0.039 & 0.684 & 0.495 & -0.981 & 2.024 \\
\hline $\begin{array}{l}\text { Frontal Assessment Battery } \\
\text { (higher score indicates better } \\
\text { performance) }\end{array}$ & -0.037 & 0.177 & -0.013 & -0.208 & 0.836 & -0.386 & 0.312 \\
\hline
\end{tabular}

EQ-5D, EuroQoL five dimensions; PROMIS, Patient Reported Outcomes Measurement Information System.

link. Robust estimates for the variances were used in all of the analysis.

Sensitivity analyses was also performed examining the possible influence of missing data on the results. The expectation-maximization (EM) algorithm was used to impute missing data in the covariates, with the imputed data entered into the linear and logistic regressions. Statistical analyses were conducted using IBM SPSS Statistics V.25. A two-sided $\mathrm{p}<0.05$ was considered statistically significant.

Patient and public involvement: no patients or the public were involved in the study protocol design, the specific aims or research questions development, or in developing plans for recruitment, design or implementation.

\section{RESULTS}

Participant characteristics are shown in table 1 . The 445 participants included in the study had an average age of $61.7 \pm 11.1$ years, $44 \%$ were women and about half selfidentified as black. Socioeconomic status was low, with over two-thirds reporting annual household income $<$ US\$25 000 and half completing less than high school education. Majority were foreign born $(72.5 \%)$, with average length of US residence of 31.4 years.

Thirty-two per cent of participants had PSD. In bivariate analyses, a significantly larger proportion of patients classified as depressed patients as contrasted with those classified as non-depressed were women, and reported lower annual household income. Those classified as depressed reported a significantly lower quality of life, and higher levels of disability as measured by the Barthel Index, the PROMIS physical function scale and the modified Rankin, which measured stroke-related functional disability. Those classified as depressed evidenced lower systolic BP and higher comorbidity. Furthermore, patients with PSD had worse scores on the Frontal Assessment Battery measuring executive function (table 1).

As shown in table 2, after adjusting for all demographics, clinical, and lifestyle variables; patients who were foreign born (OR=3.34; 95\% CI 1.40 to 7.97) evidenced higher odds of depression than those who were born in the USA those who were married or reported having a domestic partner $(\mathrm{OR}=0.46 ; 95 \%$ CI 0.24 to 0.89$)$ and those who were older ( $\mathrm{OR}=0.94$; CI 0.91 to 0.97 ) had lower odds of depression than their unmarried and younger counterparts. There was a lower odds of being depressed if participants reported higher quality of life (OR=0.02; CI 0.004 to 0.12 ). There was a trend for higher comorbidity to be uniquely associated with depression ( $\geq 3$ comorbid conditions, $\mathrm{OR}=1.49,95 \%$ CI 1.00 to 2.23 ). Sensitivity analyses treating missing data using mean imputation for the logistic regression yielded consistent results with the main analysis with the exception of PROMIS physical function, which evidenced a significant association with depression with the imputed data, but not in the main analysis (results not shown). For example, the OR estimate for 
Table 4 Cross-sectional predictors of depression among blacks and Hispanics stroke survivors with uncontrolled hypertension (bivariate results)

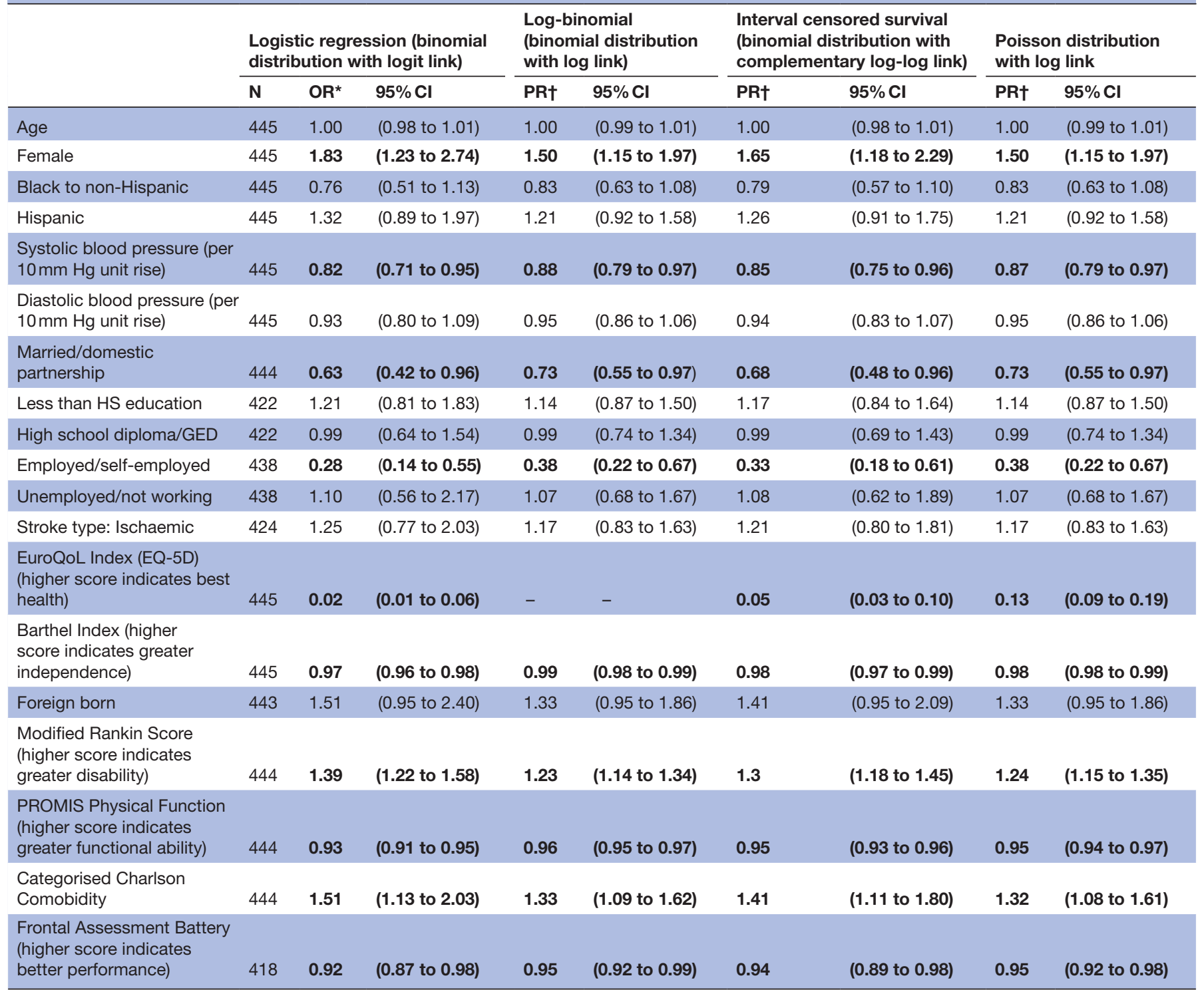

${ }^{*} \mathrm{OR}$ with $95 \% \mathrm{Cl}$ in predicting poststroke depression (PSD).

†Prevalence ratio with $95 \% \mathrm{Cl}$ in predicting PSD.

GED, General Educational Development; PROMIS, Patient Reported Outcomes Measurement Information System.

foreign born in the sensitivity analyses treating missing data was $2.79,95 \%$ CI 1.50 to $6.34 ; \mathrm{p}<0.002$.

Sensitivity analyses with a continuous depression outcome identified similar results (table 3). The only difference was that being married was not a predictor of depression in the linear regression, but was in the logistic regression (see table 3). Additionally, there was a trend $(p=0.054)$ for Hispanics to evidence lower depression. Using mean imputation for the linear regression yielded consistent results with the linear regression above.

Tables 4 and 5 show the prevalence ratios for the bivariate associations using three methods (table 4) and the multivariate results using only two methods (table 5) due to lack of convergence for the log-binomial approach. Again, results were similar to those of the primary analyses, with age, marital status, foreign born status and quality-of-life emerging as the significantly, uniquely associated with the PSD classification.

\section{DISCUSSION}

In this cohort of black and Hispanic stroke survivors with uncontrolled hypertension, the prevalence of selfreported PSD was 32\%. This is similar to the rate of PSD reported in cohorts of predominantly white stroke survivors and in previous studies of minority populations $(20.7 \%-39.3 \%)$, including those in sub-Saharan Africa. ${ }^{722} 23$ Independent correlates of PSD included being foreign born, being unmarried/not living with 
Table 5 Cross-sectional predictors of depression among blacks and Hispanics stroke survivors with uncontrolled hypertension (adjusted for demographics, clinical, and lifestyle factors $(n=278)$ )

\begin{tabular}{|c|c|c|c|c|c|c|}
\hline & \multicolumn{2}{|c|}{$\begin{array}{l}\text { Logistic regression } \\
\text { (binomial distribution } \\
\text { with logit link) }\end{array}$} & \multicolumn{2}{|c|}{$\begin{array}{l}\text { Interval censored survival } \\
\text { (binomial distribution with } \\
\text { complementary log-log link) }\end{array}$} & \multicolumn{2}{|c|}{$\begin{array}{l}\text { Poisson distribution } \\
\text { with log link }\end{array}$} \\
\hline & OR $^{*}$ & $95 \% \mathrm{Cl}$ & PRt & $95 \% \mathrm{Cl}$ & PRt & $95 \% \mathrm{Cl}$ \\
\hline Age & 0.94 & (0.91 to 0.97$)$ & 0.95 & (0.93 to 0.98$)$ & 0.97 & (0.96 to 0.99$)$ \\
\hline Female & 1.37 & (0.72 to 2.64$)$ & 1.29 & $(0.78$ to 2.13$)$ & 1.26 & (0.89 to 1.78$)$ \\
\hline Hispanic & 0.65 & (0.31 to 1.36$)$ & 0.75 & (0.43 to 1.31$)$ & 0.76 & (0.51 to 1.12$)$ \\
\hline Married/domestic partnership & 0.46 & (0.24 to 0.89$)$ & 0.59 & (0.35 to 0.98$)$ & 0.68 & (0.48 to 0.97$)$ \\
\hline Employed/self-employed & 0.44 & (0.15 to 1.35$)$ & 0.46 & $(0.18$ to 1.16$)$ & 0.51 & $(0.22$ to 1.17$)$ \\
\hline Stroke type: Ischaemic & 0.79 & (0.38 to 1.64$)$ & 0.82 & $(0.47$ to 1.41$)$ & 0.87 & (0.61 to 1.25$)$ \\
\hline $\begin{array}{l}\text { EuroQoL Index (EQ-5D) (higher score indicates best } \\
\text { health) }\end{array}$ & 0.02 & (0.00 to 0.12$)$ & 0.06 & $(0.02$ to 0.20$)$ & 0.19 & (0.10 to 0.38$)$ \\
\hline Categorised Charlson Comobidity & 1.49 & (1.00 to 2.23 ) & 1.30 & (0.96 to 1.75$)$ & 1.19 & (0.97 to 1.46$)$ \\
\hline $\begin{array}{l}\text { Frontal Assessment Battery (higher score indicates } \\
\text { better performance) }\end{array}$ & 0.94 & (0.84 to 1.05 ) & 0.94 & (0.87 to 1.03 ) & 0.97 & (0.92 to 1.03 ) \\
\hline
\end{tabular}

Significant relationships are in bold.

${ }^{*} \mathrm{OR}$ with $95 \% \mathrm{Cl}$ in predicting poststroke depression (PSD).

†Prevalence ratio with $95 \% \mathrm{Cl}$ in predicting PSD.

EQ-5D, EuroQoL five dimensions; PROMIS, Patient Reported Outcomes Measurement Information System.

a partner, older age and lower health-related quality of life. $^{24}$

Disparities in PSD rates are difficult to assess because of possible racial/ethnic differences in symptom endorsement and physician assessment and recognition. These factors may account for the Jia et al study that showed black and Hispanics were less likely to have a PSD diagnosis compared with their non-Hispanic white counterparts. ${ }^{6}$ A novel finding from our present study is that the multivariate analyses identified a significant association of foreign-born status and self-reported PSD. This is in contrast to prior studies that have found that foreignborn adults are less likely to suffer from depressive symptoms compared with US born participants. ${ }^{25-27}$ For example, Sala-Wright et $a l^{27}$ evaluated the prevalence and comorbidity of mental disorders, including depression, among immigrants to the USA. They found that immigrants were significantly less likely than US-born individuals to meet criteria for a lifetime disorder $(\mathrm{AOR}=0.63$, 95\% CI 0.57 to 0.71 ) or to report parental history of psychiatric problems. ${ }^{27}$ This may be because the rates of depression among this group are underdiagnosed or under-reported due to differences in healthcare access and utilisation or cultural factors (eg, stigma related to mental health disorders). Alternatively, lower rates of depression may reflect protective factors related to one's native country and culture. Foreign-born participants in our study had been in the USA for a mean of 31 years, so it is possible that acculturation to the USA reduced any such protective factors. This is a finding that needs to be evaluated because many of the challenges immigrants experience, including social isolation and difficulty navigating the healthcare system, would be expected to be associated with PSD.

There were several limitations to this study. The diagnosis of PSD is most appropriately based on a structured exam and Diagnostic and Statistical Manual of Mental Disorders, fourth edition (DSM-IV) criteria; however, this is difficult to perform in most clinical trials. We did not collect data on history of depression prior to the index stroke or on depression treatment. We only assessed data in the select cohort that survived the stroke event and recovered sufficiently to be discharged to the community. The cross-sectional design limits interpretations about causality. In particular, the direction of the association between PSD and health-related quality of life cannot be determined. Finally, the findings cannot be generalised to other racial/ethnic groups or to the population of stroke survivors in general because this cohort consisted exclusively of black and Hispanic community dwelling stroke survivors with uncontrolled hypertension recruited from one geographical area.

Our study also had several important strengths. In previous studies that have evaluated PSD among minorities, blacks were usually under-represented despite being most at risk for poor stroke outcomes. ${ }^{6} 7$ Unlike these studies, we included a large cohort of black and Hispanic community-dwelling stroke survivors, and the majority of participants were foreign born. The definition of depression was based on patient self-report using 
interview administered validated screening tool, not clinical reporting, allowing us to include undiagnosed depression.

\section{CONCLUSIONS}

PSD is common among black and Hispanic stroke survivors with potential for dire poststroke outcomes, including mortality. Such high rates of depression mandate screening of minority stroke survivors for depressive symptoms in order to capture the full burden of the disease in this vulnerable community. Early intervention on PSD could improve recovery and reduce morbidity and mortality related to stroke. The finding of a higher odds for PSD in foreign-born survivors is novel and warrants further research to replicate the findings, assess long-term effects of PSD in this population, and ascertain whether specific tailored depression interventions should be tested. Such efforts could improve disparities in poststroke health outcomes affecting understudied and underserved minority populations.

Acknowledgements The authors thank the Centre for Stroke Disparities Solutions Research Staff for their support and assistance with this study.

Contributors A00, SKW, JAT, OW, GO and TMS were involved in the conception and design of the study, interpreted the data and drafted the manuscript. JPE and JAT analysed the data and prepared the tables. A00, SKW, JJ and D00 were involved in data collection and reviewed the literature. All authors critically reviewed and approved the final version of the manuscript for publication.

Funding This study was funded by grant U54NS081765 from the National Institute of Neurological Disorders and Stroke of the National Institutes of Health.

Competing interests None declared.

Patient and public involvement Patients and/or the public were not involved in the design, or conduct, or reporting, or dissemination plans of this research.

Patient consent for publication Not required.

Ethics approval The Institutional Review Boards (IRB) of NYU Grossman School of Medicine, Columbia University Medical Center, and Biomedical Research Alliance of New York approved this study.

Provenance and peer review Not commissioned; externally peer reviewed.

Data availability statement All data relevant to the study are included in the article or uploaded as supplementary information.

Open access This is an open access article distributed in accordance with the Creative Commons Attribution Non Commercial (CC BY-NC 4.0) license, which permits others to distribute, remix, adapt, build upon this work non-commercially, and license their derivative works on different terms, provided the original work is properly cited, appropriate credit is given, any changes made indicated, and the use is non-commercial. See: http://creativecommons.org/licenses/by-nc/4.0/.

ORCID iD

Deborah 0 Onakomaiya http://orcid.org/0000-0003-1535-367X

\section{REFERENCES}

1 Hackett ML, Pickles K. Part I: frequency of depression after stroke: an updated systematic review and meta-analysis of observational studies. Int J Stroke 2014;9:1017-25.

2 De Ryck A, Brouns R, Fransen E, et al. A prospective study on the prevalence and risk factors of poststroke depression. Cerebrovasc Dis Extra 2013;3:1-13.
3 Ayerbe L, Ayis SA, Crichton S, et al. Explanatory factors for the association between depression and long-term physical disability after stroke. Age Ageing 2015;44:1054-8.

4 Kauhanen M, Korpelainen JT, Hiltunen P, et al. Poststroke depression correlates with cognitive impairment and neurological deficits. Stroke 1999;30:1875-80.

5 Kutlubaev MA, Hackett ML. Part II: predictors of depression after stroke and impact of depression on stroke outcome: an updated systematic review of observational studies. Int J Stroke 2014:9:1026-36.

6 Jia H, Chumbler NR, Wang X, et al. Racial and ethnic disparities in post-stroke depression detection. Int J Geriatr Psychiatry 2010;25:298-304.

7 Dong L, Sánchez BN, Skolarus LE, et al. Ethnic differences in prevalence of post-stroke depression. Circ Cardiovasc Qual Outcomes 2018;11:e004222.

8 Spruill TM, Williams O, Teresi JA, et al. Comparative effectiveness of home blood pressure telemonitoring (HBPTM) plus nurse case management versus HBPTM alone among black and Hispanic stroke survivors: study protocol for a randomized controlled trial. Trials 2015;16:97.

9 Pilkonis PA, Choi SW, Reise SP, et al. Item banks for measuring emotional distress from the patient-reported outcomes measurement information system (PROMIS $®$ ): depression, anxiety, and anger. Assessment 2011;18:263-83.

10 Teresi JA, Ocepek-Welikson K, Kleinman M, et al. Psychometric Properties and Performance of the Patient Reported Outcomes Measurement Information System ${ }^{\circledR}$ (PROMIS ${ }^{\circledR}$ ) Depression Short Forms in Ethnically Diverse Groups. Psychol Test Assess Model 2016;58:141-81.

11 Association AP. Level 2, depression, adult (PROMIS emotional distress, depression, short form). Washington, DC: American psychiatric association, 2008-2012. Available: https://www. psychiatry.org/psychiatrists/practice/dsm/educational-resources/ assessment-measures [Accessed 23 Oct 2018].

12 Charlson ME, Pompei P, Ales KL, et al. A new method of classifying prognostic comorbidity in longitudinal studies: development and validation. J Chronic Dis 1987;40:373-83.

13 EuroQol Group. EuroQol--a new facility for the measurement of health-related quality of life. Health Policy 1990;16:199-208.

14 Mahoney FI, WOOD OH, BARTHEL DW. Rehabilitation of chronically ill patients: the influence of complications on the final goal. South Med J 1958;51:605-9.

15 Fries JF, Witter J, Rose M, et al. Item response theory, computerized adaptive testing, and PROMIS: assessment of physical function. $J$ Rheumatol 2014;41:153-8.

16 Wilson JTL, Hareendran A, Grant M, et al. Improving the assessment of outcomes in stroke: use of a structured interview to assign grades on the modified Rankin scale. Stroke 2002;33:2243-6.

17 Dubois B, Slachevsky A, Litvan I, et al. The Fab: a frontal assessment battery at bedside. Neurology 2000;55:1621-6.

18 Tamhane AR, Westfall AO, Burkholder GA, et al. Prevalence odds ratio versus prevalence ratio: choice comes with consequences. Stat Med 2016;35:5730-5.

19 Box GEP, Tidwell PW. Transformation of the independent variables. Technometrics 1962;4:531-50.

20 Barros AJD, Hirakata VN. Alternatives for logistic regression in crosssectional studies: an empirical comparison of models that directly estimate the prevalence ratio. BMC Med Res Methodol 2003;3:21.

21 Coutinho LMSet al. Methods for estimating prevalence ratios in cross-sectional studies. Rev Saúde Pública 2008;42.

22 Fei K, Benn EKT, Negron R, et al. Prevalence of depression among stroke survivors: Racial-Ethnic differences. Stroke 2016;47:512-5.

23 Ojagbemi A, Akpa O, Elugbadebo F, et al. Depression after stroke in sub-Saharan Africa: a systematic review and meta-analysis. Behav Neurol 2017;2017:1-9.

24 Robinson RG. The controversy over post-stroke depression and lesion location. Psychiatric Times 2003;20:39.

25 Fang J, Yuan K, Gindi RM, et al. Association of Birthplace and Coronary Heart Disease and Stroke Among US Adults: National Health Interview Survey, 2006 to 2014. J Am Heart Assoc 2018;7:e008153.

26 Sohail QZ, Chu A, Rezai MR, et al. The risk of ischemic heart disease and stroke among immigrant populations: a systematic review. Can J Cardiol 2015;31:1160-8.

27 Salas-Wright CP, Vaughn MG, Goings TC, et al. Immigrants and mental disorders in the United States: new evidence on the healthy migrant hypothesis. Psychiatry Res 2018;267:438-45. 